\title{
The Effects of Some Mechanical Parameters of a Developed Millet Thresher on Millet Threshing and Cleaning Efficiencies
}

\author{
Gana Ibrahim Mohammed, Baba Adamu Musa, Gbabo Agidi, Shehu Abubakar Alhaji
}

\begin{abstract}
Some mechanical and process parameters of a developed millet thresher have been optimized using a numerical optimization technique. The machine threshes millet panicles and cleans the grains from the straw. The speed of threshing and the number of pegs attached to the threshing drum were mechanical parameters investigated, while the moisture content was the process parameter under investigation. Threshing efficiency, cleaning efficiency, and percentage losses were used as performance characteristics while investigating these parameters. A central composite rotatable design was used in the experiment (CCRD). The results of the experiments revealed that the speed of threshing and the number of beater pegs had significant positive effects on threshing efficiency, whereas the millet panicle had significant negative effects. The speed of threshing and the number of beater pegs had considerable positive effects on threshing efficiency, whereas the millet panicle had large negative effects, according to the results of the studies. Also, a combination of a speed of $1590 \mathrm{rpm}, 28$ beater pegs, and a millet panicle moisture of $15 \%$ resulted in the maximum cleaning efficiency of 98.31\%. The cleaning speed had a positive substantial effect on the cleaning efficiency, although the beater pegs and moisture content had small effects. The optimum speed of $1730 \mathrm{rpm}$, number of pegs of 35, and millet moisture content of 13.5 percent for threshing efficiency of 91.41 percent, cleaning efficiency of 97.87, and desirability of 0.997 were achieved using numerical optimization. The study's findings include standard input machines and processing variables that produce the best machine output
\end{abstract}

Keywords: Millet; optimization, parameters, thresher

\section{INTRODUCTION}

Millets are small-seeded grains that come in a variety of forms, including pearl millet (Pennisetum glaucum) and

Manuscript received on 11 July 2021 | Revised Manuscript received on 29 July 2021 | Manuscript Accepted on 15 August 2021 | Manuscript published on 30 August 2021.

* Correspondence Author

Gana Ibrahim Mohammed*, Senior Lecturer, Department of Agricultural and Bioenviromental Engineering, Federal Polytechnic, Bida, Nigeria. Email: ganaibro74@yahoo.com

Baba Adamu Musa*, Lecturer, Department of Agricultural and Bioenviromental Engineering Technology, Federal Polytechnic, Nasarawa, Nigeria. Email: babaadamum50@yahoo.com

Gbabo Agidi, Associate Professor, Department of Agricultural and Bioresources Engineering, Federal University of Technology, Minna, Nigeria. Email: agidides@yahoo.com

Shehu Abubakar Alhaji, Lecturer, Department of Agricultural and Bioenviromental Engineering, Federal Polytechnic, Bida, Nigeria. Email: shehuaa2000@yahoo.com

(c) The Authors. Published by Lattice Science Publication (LSP). This is an open access article under the CC-BY-NC-ND license (http://creativecommons.org/licenses/by-nc-nd/4.0/) finger millet (Eleusine coracana). Millet provides human beings with nutritional and livelihood security, as well as feed security for a variety of livestock populations [1]. More especially now the world is faced with danger of Climate change, rising food prices, and other socioeconomic effects. As a result, agricultural mechanization must be adopted as one of the best options for reducing hunger and poverty. Before it reaches the consumer's table, millet, like other agricultural raw materials, goes through a variety of post-harvest unit processes. Threshing, separation, and cleaning are examples of these activities. The machine mechanical parameters determine the operation and performance of a thresher. Higher threshing loss and grain damage arise from incorrectly adjusted threshers or selection of these parameters, and thus, affect the quality and quantity of the end output. By analysis using an optimization technique, the best machine parameter is obtained. An experimental design (DOE) is frequently used in agriculture and industry to enhance methods, product design, and process parameter setting. When employing DOE, the response surface methodology (rsm) is typically utilized to find the best parameter/setting once the variables have been examined to find significant variables. The response surface is graphically characterised using a contour plot, which confirms the most effective parameter/set setting. When numerous responses are taken into account, perceptive overlay contour plots, as depicted by [2], yield the most effective parameter/setting. The response function is a polynomial, according to [3], and it accurately reflects the real interaction. The central composite design, according to [4], is one of the most commonly utilized response surface designs for fitting a quadratic model. The central composite design (CCD) is made up of three parts: factorial points, center points, and axial points. It's usually done by adding points to a $2 \mathrm{P}$ design that's already been completed, and in CCD, each factor has five levels; extreme high, high, center, low, and extreme low. Many studies have stated that there are two alternatives for central composite designs: center point range and axial point location. Selecting the axial points at $(\mathrm{P}, 0 \ldots 0)$ e.t.c. with $\mathrm{P}=$ (factorial points $) 1 / 4$ makes the design rotatable, suggesting that the model's correctness is exclusively governed by the distance from the origin [4]. A novel approach for optimizing many reactions simultaneously in designed experiments was reported by [5] To construct the experiments in accordance with the authors, an acceptable experimental design is first determined.

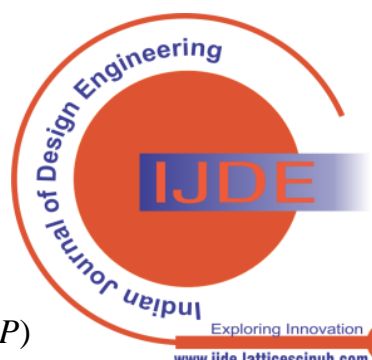


After that, each Data Analysis (DEA) and Response Surface Technique is subjected to the analysis of experimental data (RSM). Finally, the parameter - set with the highest potency is chosen as the ideal parameter setting.

\section{Optimisation of Numerous Responses with Aid Response Surface Method}

Optimization is the process of experimenting to arrive at a variable situation that produces a desirable process output. This includes determining the number of experiments to run, as well as the variable level mix and cost implications. Surface response methodology (RSM) is an empirical statistical method used in modeling problems where several elements influence a fascinating reaction, according to [6]. The regression analysis generated by the higher energy equation is displayed in RSM as the estimated association between one dependent factor (quite close to the genuine solution) and several independent factors. To study an ideal solution, this equation is known as a response function and is usually visually depicted as a response surface. In a multivariable section, a low-order polynomial is typically utilized [6]. Assume that $Y$ denotes the response and $X_{q}$ denotes the variables, $g=1, \ldots N$, a linear function of variables can effectively model the response, then the response surface is a first - order model and is given as follows

$Y=\beta_{0}+\beta_{1} X_{1}+\beta_{2} X_{2}+\cdots \ldots+\beta_{N} X_{N}$

where, $\beta_{\mathrm{g}}$ is the regression coefficient, $\mathrm{g}=1, \ldots \mathrm{N}$.

When specifying curvature as a response surface a polynomial of a high order is appropriate for the response surface. For instance, a second - order model of the response surface is $\mu$

$Y=\beta_{0}+\sum_{g=1}^{N} \beta_{g} x_{g}+\sum_{g=1}^{N} \beta_{g g} x_{g}^{2}+\sum_{g<f} \sum \beta_{g f} x_{g} x_{f}$

The fitted response surface is a good indication of the actual response function if an appropriate model is used. Moreover, when good designs are employed to obtain experimental data, model parameters can be computed quickly [6]. The aim of this research is to optimize certain mechanical and process parameters of a advanced millet thresher created by [6].

\section{METHODOLOGY}

\section{A. Millet panicle samples preparation}

Thirty kilograms of millet panicle were supplied by a farmer in Jima Village, Lavun Local Government Area, Niger State, Nigeria. Before being divided into twenty samples of $1.5 \mathrm{~kg}$ each, it was sorted and cleaned to remove foreign components. Then, utilizing the developed millet thresher and the design matrix presented in Table 1, the clean samples were processed.

\section{B. Equipment}

A millet thresher developed by [6] shown in Figure 1, was used in this study. The machine threshes millet seeds, separates them, and cleans them. Threshing, separation, and cleaning units are among the machine's primary components. The threshing operation is carried out by rotating a cylinder with beater pegs above a stationary grid, resulting in the removal of the seeds from the panicles and their separation from the majority of the straw. After being beaten out, the grains fall into the cleaning unit through a concave grid made up of two reciprocally moving sieves. A continual blast of air is directed at the grains as they pass through these sieves.

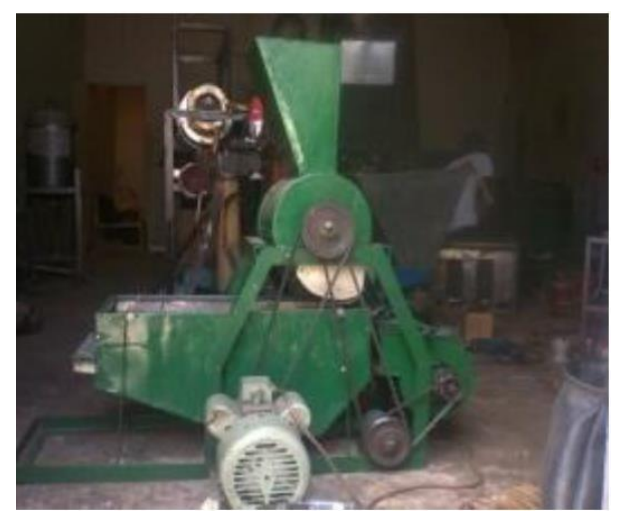

Fig. 1.The developed millet thresher and cleaner

\section{Experimental setup and plan}

Using a central composite rotatable design (CCRD), a surface response methodology was applied in this study. It consists of three variables with five levels of variation [6]. The CCRD is made up of 20 experimental runs $(2 k+2 k+m$, where $k$ denotes the number of variables and $m$ denotes the number of replicated center points), each with eight factor points (2k), six axial points (2k), and six replicated center points $(m=6)$. The axial point has a value of 1.68 and $k$ independent variables. The CCRD center point for each factor was generated using data from previous studies [7]. Shelling speed and the number of beater pegs were two mechanical characteristics of the machine, while millet moisture content was a process parameter. The shelling speed ranged from 1920 to $1750 \mathrm{rpm}, 1500$ to $1250 \mathrm{rpm}$, and $1080 \mathrm{rpm}$. Beater pegs ranged in number from $16,21,28,35$, and 40 . The moisture content of millet was also varied from 12.48 percent, 13.5 percent, 15 percent, 16.5 percent, and 17.53 percent. Table 1 shows the design matrix used in the experiment. The independent variables were the machine's mechanical and processing parameters, whereas the dependent variable (response) was millet threshing efficiency.

\section{Experimental procedure}

The machine component parts were assembled as reported by [7]. The millet panicles entered the threshing drum through the hopper. The panicle's grains were beaten out and separated from the straw's bulk. A cylinder with beater pegs rotating over a stationary grid known as a concave was used to accomplish this. The grains were hammered out between the bars and the cylinder pegs on the concave, which was also fitted with bars along its length. The majority of the grain falls into the concave grid.

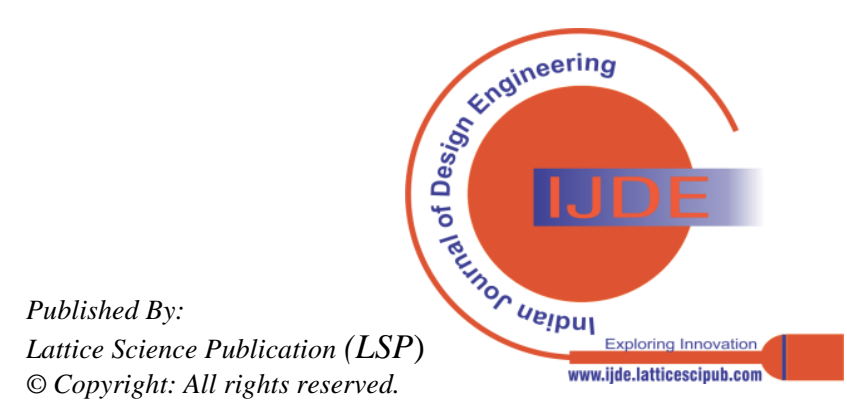


The millet is threshed and delivered in the cleaning unit, which consists of two sieves that are shaken and a centrifugal fan that blows air into the sieves. The top sieve keeps the chaff in place while allowing the grains to flow through to the lower sieve, known as the grain sieve, which has holes around the size of the grain size. The grain sieve's purpose is to separate the grain from waste, sand, and broken grain. The air forced through these sieves by the blower prevents heavier weight debris from settling on the sieve. The cleaned grain is conveyed to the collection unit by the grain pans beneath the grain sieve, while the broken grains and other particles smaller than the grain are conveyed to the opposite outlet by the other pan.

\section{E. Evaluation of the machine parameters}

Threshing efficiency (TE): It is the mass of threshed millet divided by the overall mass of the millet panicle expressed in percentage as reported by [7] and is given as:

$$
T_{E}=\frac{M_{F}}{M_{\varphi}} \times 100
$$

Where, $T E$ is the threshing efficiency (\%), $M T$ is mass of threshed millet (g), MP is the mass of the total mass of millet panicle (g).

Cleaning efficiency (CE): It is the ratio of mass of separated impurities to the total mass of impurities in the millet expressed in percentage as reported by [7] and is given as:

$$
C_{E}=\frac{M_{S I}}{M_{U I}} \times 100
$$

Where, $C_{E}$ is the cleaning efficiency (\%), $M_{\triangle I}$ is mass of separated impurities (g), $M_{U I}$ is the mass of un-separated impurities (g)

\section{F. Statistical analysis}

Design expert software package (version 7.0.0) was used for regression and graphical analysis. A quadratic polynomial equation was developed to predict reaction as a function of independent variables and their interaction. The effects of primary parameters, as well as their potential interaction effects, on threshing efficiency, cleaning efficiency, and percentage losses, were analyzed using analysis variance (ANOVA) as reported by [6].

\section{G. Optimisation analysis}

The process of determining the optimal solution for a system or operation is known as optimization. The basic goal of optimization is to get the best operating conditions for a system or machine [6]. The optimization analysis of the independent and dependent variables was carried out in this study using the design expert's software numerical technique.

\section{RESULT AND DISCUSSION}

Table 1 shows the effects of independent variables such as threshing speed, number of beater pegs, and moisture content of the millet panicle on threshing and cleaning efficiencies.

\begin{tabular}{|c|c|c|c|c|c|c|c|c|}
\hline $\begin{array}{l}\text { Standard } \\
\text { order }\end{array}$ & $\begin{array}{l}\text { Run } \\
\text { order }\end{array}$ & $\begin{array}{l}\text { Speed } \\
\text { (rpm) }\end{array}$ & $\begin{array}{l}\text { Number of } \\
\text { pegs (No) }\end{array}$ & $\begin{array}{l}\text { Moisture } \\
\text { content of } \\
\text { Millet panicles } \\
(\%)\end{array}$ & $\begin{array}{l}\text { Actual value } \\
\text { of Threshing } \\
\text { efficiency } \\
(\%)\end{array}$ & $\begin{array}{l}\text { Predicted value } \\
\text { of Threshing } \\
\text { efficiency }(\%)\end{array}$ & $\begin{array}{l}\text { Actual value } \\
\text { of cleaning } \\
\text { efficiency } \\
(\%)\end{array}$ & $\begin{array}{l}\text { Predicted value } \\
\text { of cleaning } \\
\text { efficiency (\%) }\end{array}$ \\
\hline 17 & 1 & 1500 & 28 & 15 & 69.00 & 68.99 & 98.31 & 97.13 \\
\hline 11 & 2 & 1500 & 16 & 15 & 48.00 & 49.18 & 92.42 & 91.6 \\
\hline 3 & 3 & 1250 & 35 & 13.5 & 50.66 & 50.99 & 52.92 & 53.57 \\
\hline 10 & 4 & 1920 & 28 & 15 & 77.75 & 78.62 & 77.51 & 76.74 \\
\hline 1 & 5 & 1250 & 21 & 13.5 & 36.20 & 37.56 & 58.42 & 58.99 \\
\hline 7 & 6 & 1250 & 35 & 16.5 & 44.85 & 45.86 & 59.54 & 60.14 \\
\hline 9 & 7 & 1080 & 28 & 15 & 27.23 & 26.6 & 17.01 & 16.1 \\
\hline 5 & 8 & 1250 & 21 & 16.5 & 39.25 & 37.45 & 57.65 & 58.31 \\
\hline 16 & 9 & 1500 & 28 & 15 & 69.00 & 68.99 & 97.67 & 97.13 \\
\hline 13 & 10 & 1500 & 28 & 12.48 & 75.00 & 73.65 & 96.00 & 95.19 \\
\hline 20 & 11 & 1500 & 28 & 15 & 70.00 & 68.99 & 95.00 & 97.13 \\
\hline 8 & 12 & 1750 & 35 & 16.5 & 72.00 & 70.47 & 91.83 & 92.44 \\
\hline 12 & 13 & 1500 & 40 & 15 & 72.50 & 71.56 & 91.22 & 90.38 \\
\hline 4 & 14 & 1750 & 35 & 13.5 & 91.41 & 93.02 & 95.01 & 95.53 \\
\hline 18 & 15 & 1500 & 28 & 15 & 70.00 & 68.99 & 97.54 & 97.13 \\
\hline 15 & 16 & 1500 & 28 & 15 & 69.00 & 68.99 & 97.67 & 97.13 \\
\hline 14 & 17 & 1500 & 28 & 17.52 & 53.00 & 54.59 & 92.87 & 92.01 \\
\hline 6 & 18 & 1750 & 21 & 16.5 & 57.80 & 57.29 & 87.92 & 88.46 \\
\hline 2 & 19 & 1750 & 21 & 13.5 & 76.00 & 74.81 & 98.23 & 98.81 \\
\hline 19 & 20 & 1500 & 28 & 15 & 67.00 & 68.99 & 96.31 & 97.13 \\
\hline
\end{tabular}

Table- I: Interaction between dependent and independent variables of the machine

\section{Threshing efficiency}

The threshing efficiency ranged from $27.23 \%$ to $91.41 \%$. The highest value of $91.41 \%$ was obtained from a combination of speed of $1750 \mathrm{rpm}, 35$ beater pegs, and millet panicle moisture of $13.5 \%$, while the least threshing efficiency of $27.23 \%$ was obtained from an interaction between speed of 1080 rpm, 28 beater pegs, and millet panicle moisture of $15 \%$.
The result of the statistical analysis of variance (ANOVA) of threshing efficiency presented in Table II showed that the model terms were significant.

$T E=68.99+15.47 A+6.65 B-5.67 C-4.36 A C-5.79 A 2-$ $3.05 B^{2}-1.72 C^{2}$

(6)

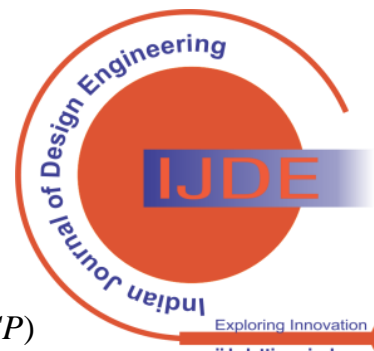


The Effects of Some Mechanical Parameters of a Developed Millet Thresher on Millet Threshing and Cleaning Efficiencies

Table- II: Regressed result of threshing efficiency

\begin{tabular}{|c|c|c|c|c|c|c|c|}
\hline Source & $\begin{array}{c}\text { Coefficient } \\
\text { Estimate }\end{array}$ & $\begin{array}{c}\text { Standard } \\
\text { Error }\end{array}$ & $\begin{array}{l}\text { Mean } \\
\text { Square }\end{array}$ & $\begin{array}{c}\text { F } \\
\text { Value }\end{array}$ & $\begin{array}{l}\text { p-value } \\
\text { Prob > F }\end{array}$ & $\begin{array}{c}\text { R-Squared } \\
\text { value }\end{array}$ & \\
\hline Model & 68.99 & 0.6654 & 563.35 & 211.61 & $<0.0001$ & 0.9948 & significant \\
\hline A-Speed & 15.46 & 0.4415 & 3266.5 & 1227.02 & $<0.0001$ & & \\
\hline $\begin{array}{c}\text { B-Number } \\
\text { of pegs }\end{array}$ & 6.65 & 0.4415 & 604.68 & 227.13 & $<0.0001$ & & \\
\hline $\begin{array}{l}\text { C-Moisture } \\
\text { content }\end{array}$ & -5.66 & 0.4415 & 438.31 & 164.64 & $<0.0001$ & & \\
\hline $\mathrm{AB}$ & 1.19 & 0.5768 & 11.40 & 4.28 & 0.0654 & & \\
\hline $\mathrm{AC}$ & -4.35 & 0.5768 & 151.81 & 57.02 & $<0.0001$ & & \\
\hline $\mathrm{BC}$ & -1.25 & 0.5768 & 12.67 & 4.76 & 0.0541 & & \\
\hline$A^{\wedge} 2$ & -5.79 & 0.4298 & 483.25 & 181.52 & $<0.0001$ & & \\
\hline $\mathrm{B}^{\wedge} 2$ & -3.04 & 0.4298 & 133.81 & 50.26 & $<0.0001$ & & \\
\hline$C^{\wedge} 2$ & -1.72 & 0.4298 & 42.70 & 16.04 & 0.0025 & & \\
\hline Lack of Fit & & & 4.12 & 3.43 & 0.1008 & & $\begin{array}{c}\text { not } \\
\text { significant }\end{array}$ \\
\hline
\end{tabular}

The 95 percent significance criterion was used to identify the significant model terms. Equations 5 and 6 indicate the regression model equations developed to predict threshing efficiency with respect to independent variables. The fact that the threshing efficiency model $F$ has a value of 211.61 indicates that it is noteworthy. An F-value of this magnitude has a 0.01 percent chance of occurring due to noise. The model terms were significant if the Probability $>\mathrm{F}$ value was less than 0.0500. A, B, C, AC, A2, B2, and C2 are important model terms in this situation. The 3.44 "Lack of Fit F-value" suggests that the lack of fit is minimal compared to pure error. There is a $10.08 \%$ chance that a "Lack of Fit F-value" this large value could occur due to noise. Non-significant lack of fit is good [8]. According to [9], a low coefficient of variation (C.V.) as the value of 2.64 percent was obtained, indicated that the discrepancy between experimental and predicted values was small. The coefficient of determination (R) value of 0.9974 indicated that the model could predict 99.74 percent of the variance, with only 0.26 percent of the total variance remaining unaccounted for. As reported by [10], the coefficient of correlation (R- Squared) value of 0.9948 was strong and extremely close to one. Adequate precision of 57.57 is above the desired minimum value of 4 reported by [11]. This indicated that the model can be used to navigate the design space.

The regressed threshing efficiency model equation is given as:

$T E=68.99+15.47 A+6.65 B-5.67 C+1.19 A B-4.36 A C-$

$1.26 B C-5.79 A 2-3.05 B^{2}-1.72 C^{2}$

Where, TE is the threshing efficiency (\%), A is speed of threshing (rpm), B is the number of pegs (No), C is the moisture content (wet bases) of the millet panicle (\%).

By eliminating irrelevant model terms, the model equation was improved. The model terms $\mathrm{AB}$ and $\mathrm{BC}$ are not significant with $\mathrm{P}$-values greater than 0.05 . As a result, equation 6 was used to simplify the model [8].

The fitted threshing efficiency model equation is given as:

The positive coefficient of variables A (speed) and B (pegs) in the model imply direct proportionality, however the negative coefficient of variable $C$ (moisture content) implies indirect proportionality. That is an increase in A and B enhances the threshing efficiency. The independent increase in $\mathrm{C}$, on the other hand, decreased the threshing efficiency.
The derived model equation was simulated, and the actual threshing efficiency values were found to be quite near to the predicted values, as shown in Table I.

Response surface and contour plot for threshing efficiency with respect to interaction between speed and number of pegs

Figures 2 and 3 show the response surface and contour plot for millet threshing efficiency as a function of interaction between speed and number of pegs at a constant moisture content of $15 \%$, respectively. When the threshing speed was increased from $1080 \mathrm{rpm}$ to $1710 \mathrm{rpm}$, the threshing efficiency increased from $25 \%$ to $85 \%$, but subsequently reduced to 83 percent when the speed was increased to 1920 rpm.

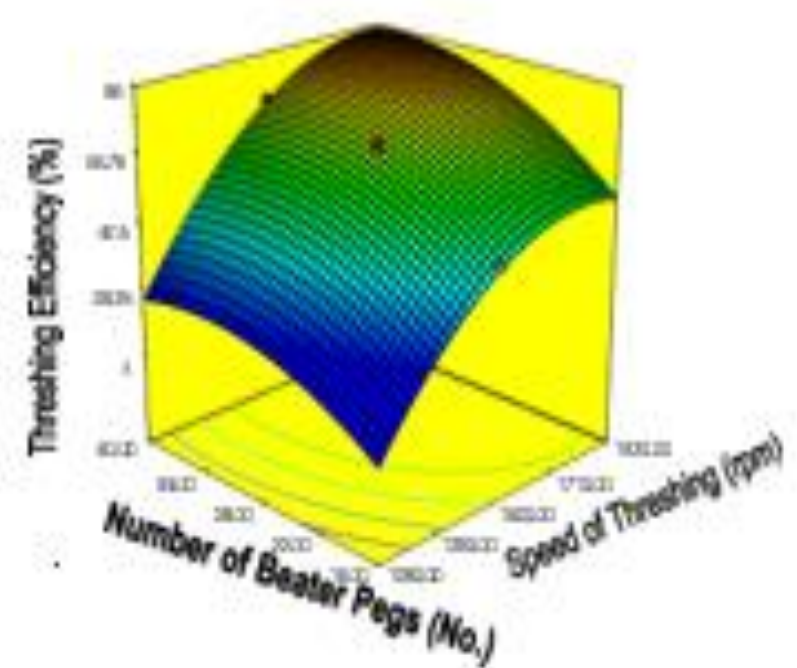

Fig. 2.Response surface for threshing efficiency with respect to interaction between speed of threshing and number of pegs

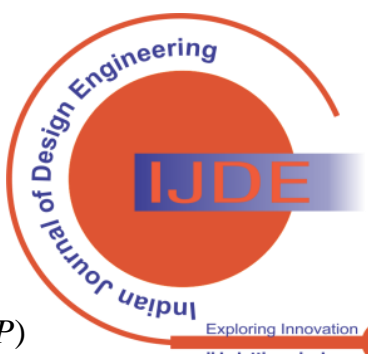




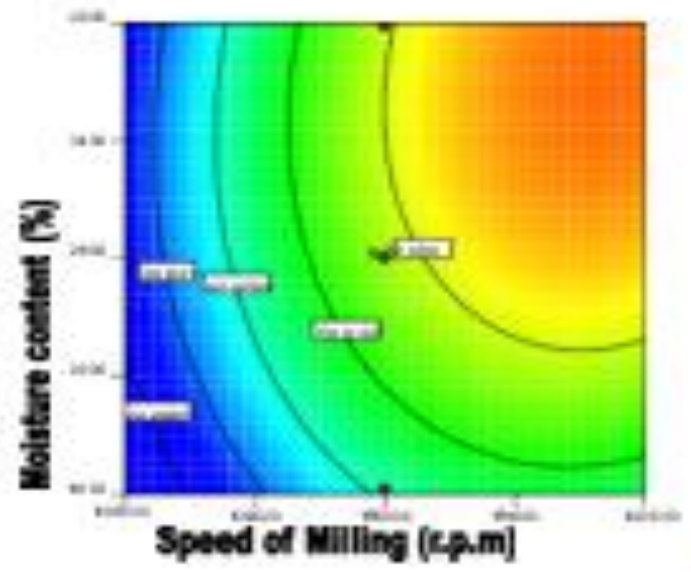

Fig. 3.Contour Plot for threshing efficiency with respect to interaction between speed of threshing and number of pegs

This could be due to the millet stalk being impacted by the beaters. This is consistent with the findings of a previous study by [7] on the design, manufacture, and testing of millet threshers, which found that higher threshing drum rotation speeds resulted in more impact. The rupture of the grains caused by the increased impact force associated with the higher speed may explain the further loss in threshing efficiency with an increase in speed from $1710 \mathrm{rpm}$ to 1920 rpm. With an increase in beater pegs from 16 to 35 numbers, the machine's threshing efficiency increased to 83 percent, then remained constant with a further increase to 40 numbers.

Response surface and contour plot for threshing efficiency with respect to interaction between number of pegs and moisture content

Figures 4 and 5 show the response surface and contour plot for millet threshing efficiency as a function of the interaction between the number of beater pegs and moisture content. With an increase in beater pegs from 16 to 34, millet threshing efficiency increased from 48 percent to 80 percent, then remained stable with successive increases in beater pegs. This could be owing to the millet panicles' greater impact action from the pegs.

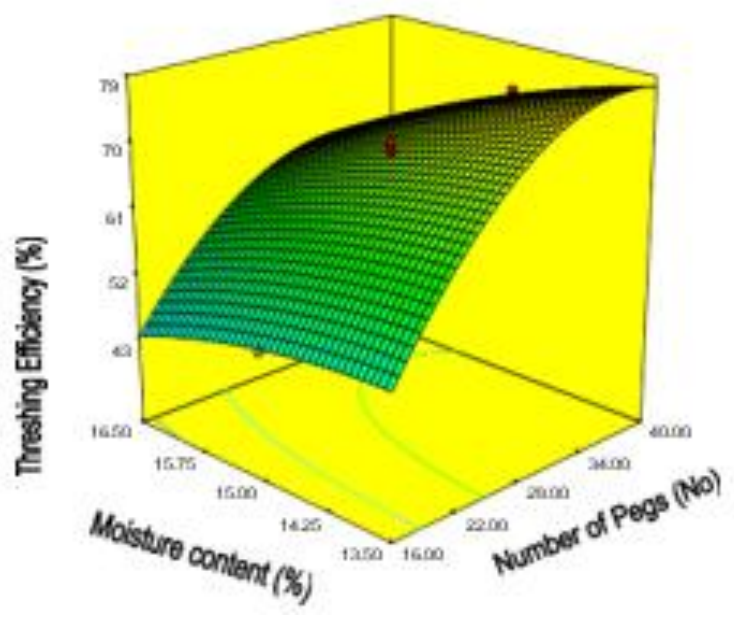

Fig. 4.Response Surface for threshing efficiency with respect to interaction between moisture content and number of pegs

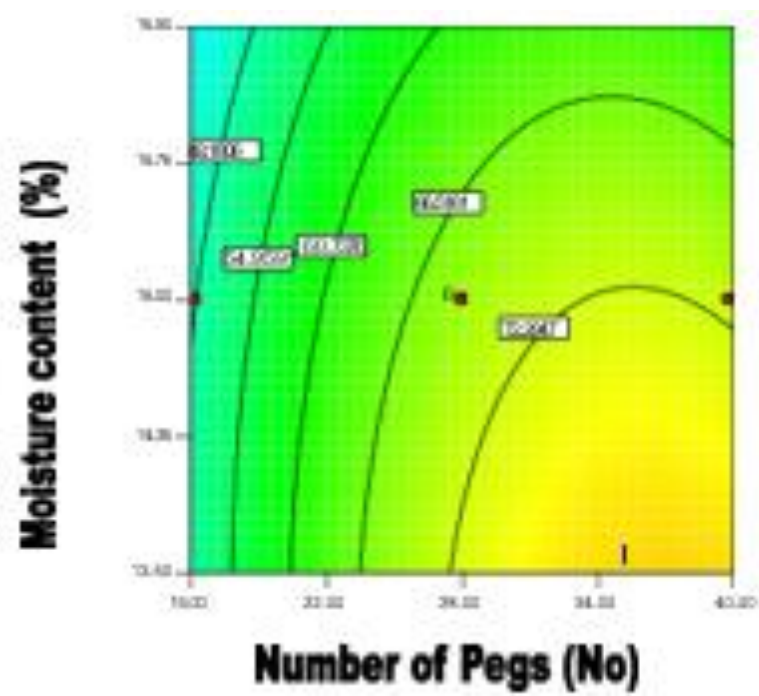

Fig. 5.Contour Plot for threshing efficiency with respect to interaction between moisture content and number of pegs

This replicated the findings of a previous study by [12], where the number of spike teeth cylinders employed in a thresher affected its threshing performance. The threshing efficiency, on the other hand, reduced from 48.3 percent to 12.48 percent while the moisture content of the millet panicles increased from 12.48 percent to 17.52 percent. In general, threshing efficiency rises with lower moisture content and falls with higher moisture level. This could be due to the millet stalk's dryness, which permits the grains to easily dislodge from the stalk. This corroborated the findings of a previous study by [13], who found that lowering the moisture level of unthreshed grains increased threshing and extractor efficiency. This could be a result of increased in impact action of the pegs with increased in number of pegs. This agreed with the result of an earlier study conducted by [12], where threshing effectiveness of a thresher was found to be affected by the cylinder speed, the concave clearance, feed rate of crops, the number of rows of concave teeth used with spike tooth cylinder, and the type of crop.

\section{Cleaning efficiency}

Cleaning efficiency ranged from $17.1 \%$ to $98.31 \%$. A combination of $1590 \mathrm{rpm}, 28$ beater pegs, and 15\% millet panicle moisture yielded the best threshing efficiency of $98.31 \%$, whereas an interaction of 1080 rpm, 28 beater pegs, and $15 \%$ millet panicle moisture yielded the lowest threshing efficiency of 17.01 percent. The model terms were significant, according to the results of a statistical analysis of variance (ANOVA) of cleaning efficiency. The 95 percent significance criterion was used to identify the significant model terms. Equations 7 and 8 indicate the regression model equations created to predict cleaning efficiency with respect to independent factors. Cleaning efficiency model $\mathrm{F}$ has a value of 708.72, indicating that it is substantial. An F-value of this magnitude has a 0.01 percent chance of occurring due to noise. 
The model terms were significant if Probability $>\mathrm{F}$ was less than 0.0500. A, AC, BC, A2, B2, and C2 are crucial model terms in this situation. When compared to a pure error, the "Lack of Fit F-value" of 0.96 indicates that the lack of fit is statistically insignificant. Due to noise, there is a 51.82 percent chance that a "Lack of Fit F-value" of this huge number will occur. Non-significant lack of fit is good [8]. A low coefficient of variation (C.V.) is desirable, according to [9]. As a result, the $1.45 \%$ value obtained suggests that the difference between experimental and expected values was less. Due to noise, an F-value of 708.72 has a 0.01 percent probability of occurring. The coefficient of determination (R) value of 0.9992 indicated that the model could predict 99.92 percent of the variance while 0.08 percent of the total variation. As indicated by [10], the coefficient of correlation (R-Squared) value of 0.9984 was strong and extremely close to 1 . According to [11], the adequate precision of 97.57 is higher than the recommended minimum value of 4 . This means the model can be used to navigate across the design space.

The regressed cleaning efficiency model equation is given as:

$C E=97.13+18.03 A-0.36 B-0.94 C+0.54 A B-2.42 A C$

$+1.82 B C-17.93 A 2-2.17 B 2-1.25 C 2$
Where, $C E$ is the cleaning efficiency (\%), A is speed of threshing (rpm), B is the number of pegs (No), C is the moisture content (wet bases) of the millet panicle (\%).

By eliminating the insignificant model terms, the model equation was improved. The model terms $B, C$, and $A B$ are not significant if since their $\mathrm{P}$-values are greater than 0.05 . As a result, the model was simplified to equation 8 [8].

The fitted cleaning efficiency model equation is given as:

$$
C E=97.13+18.03 A-2.42 A C+1.82 B C-17.93 A 2-
$$

$2.17 B 2-1.25 C 2$

In the model, the significant variable A (speed) has a clear positive co-efficient, implying direct proportionality. That is a distinct improvement in cleaning efficiency. The efficiency was observed to be within the experimental range using the model equation produced, as shown in Table I.

\section{Response Surface and Contour Plot for Cleaning Efficiency}

Figures 8 and 9 show the response surface and contour plot for millet cleaning efficiency as a function of interaction between speed and peg count. Cleaning efficiency increased from $17 \%$ to $98 \%$ as the cleaning speed increased from 1080 to $1500 \mathrm{rpm}$, then declined to $64 \%$ as the speed increased to $1920 \mathrm{rpm}$

Table- II: Regressed result of cleaning efficiency

\begin{tabular}{|c|c|c|c|c|c|c|c|}
\hline Source & $\begin{array}{c}\text { Coefficient } \\
\text { Estimate }\end{array}$ & $\begin{array}{c}\text { Standard } \\
\text { Error }\end{array}$ & $\begin{array}{c}\text { Mean } \\
\text { Square }\end{array}$ & $\begin{array}{c}\text { F } \\
\text { Value }\end{array}$ & $\begin{array}{c}\text { p-value } \\
\text { Prob }>\text { F }\end{array}$ & $\begin{array}{c}\text { R-squared } \\
\text { Value }\end{array}$ & $\begin{array}{c}<0.0001 \\
0.9984\end{array}$ \\
\hline Model & 97.13 & 0.4889 & 1018.54 & 708.72 & significant \\
\hline A-Speed & 18.02 & 0.3243 & 4438.69 & 3088.53 & $<0.0001$ & \\
\hline B-Number of pegs & -0.36 & 0.3243 & 1.78 & 1.2424 & 0.2911 & & \\
\hline C-Moisture content & -0.94 & 0.3243 & 12.19 & 8.4839 & 0.0155 & & \\
\hline AB & 0.53 & 0.4238 & 2.31 & 1.6082 & 0.2335 & \\
\hline AC & -2.41 & 0.4238 & 46.75 & 32.5327 & 0.0002 & \\
\hline BC & 1.81 & 0.4238 & 26.35 & 18.3375 & 0.0016 & \\
\hline $\mathrm{A} \wedge 2$ & -17.92 & 0.3157 & 4631.83 & 3222.93 & $<0.0001$ & & \\
\hline $\mathrm{B} \wedge 2$ & -2.17 & 0.3157 & 68.07 & 47.3666 & $<0.0001$ & \\
\hline $\mathrm{C} \wedge 2$ & -1.24 & 0.3157 & 22.47 & 15.6391 & 0.0027 & \\
\hline Lack of Fit & & & 1.40 & 0.9579 & 0.5182 & \\
\hline
\end{tabular}

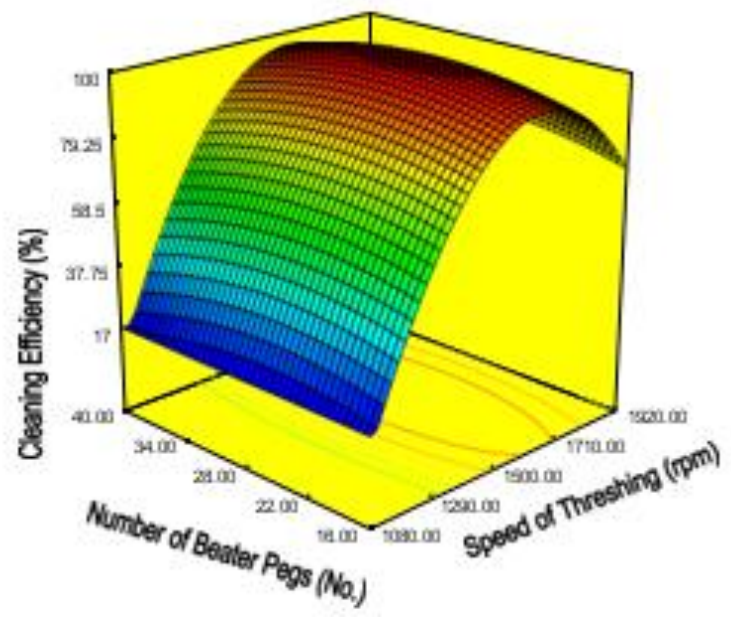

Fig. 6.Response Surface for Cleaning efficiency with respect to interaction between speed and number of pegs

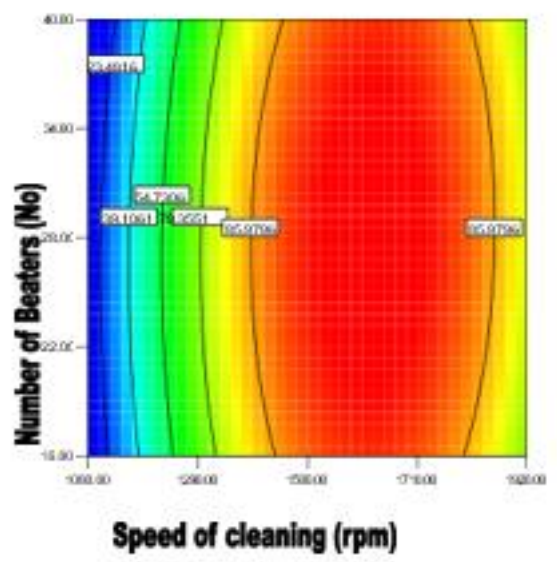

Fig. 7.Contour Plot for Cleaning efficiency with respect to interaction between speed and number of pegs 
The first gain in cleaning effectiveness as the cleaning speed increased from 1080 to $1500 \mathrm{rpm}$ could be due to the air velocity being sufficient to carry just lighter materials. However, as the speed of the air increased, the air velocity increased as well. The air velocity is sufficient at this time, and it lifts and carries away portion of the millet seed along with the lighter chaff. This was consistent with the findings of an earlier study by [14], where high cleaning speeds resulted in increased air velocity, which fluidized the grain and carried it to the back of the sieve, where it was deposited with the chaff. The number of beaters and the amount of moisture in the air had no discernible effect on the cleaning efficiency.

\section{Optimisation of the machine functional parameters}

The optimum values of speed of $1730 \mathrm{rpm}, 33$ pegs, and millet panicle moisture content of 13.5 percent for desirability 0.997, threshing and cleaning efficiencies of 91.41 percent and 97.87 percent, respectively, were obtained by optimizing with the goal of maximising the threshing and cleaning efficiencies

\section{CONCLUSION}

Millet threshing and cleaning efficiency are affected by millet moisture content, speed of threshing, velocity of air used for cleaning, and the number of beaters. The higher the moisture content of the millet panicle, the more difficult it becomes to separate the millet seed from the stalks. On the other hand, lower moisture content resulted in breakage of the speed of the stalk even before threshing. This increased post harvest losses of the seeds. A threshing speed that is too high or too low is not desirable, as a high-speed result in breakage and, in some cases, grinding of the seed during threshing. Furthermore, the number of beaters has a significant impact on threshing efficiency. The greater the number of beaters, the greater the impact on the panic, whereas the lesser the number, the lower the impact and, as a result, less threshing efficiency. The velocity of the air blast is a very important factor in the cleaning or separation of the threshed millet from the chaff. If the air velocity is above the terminal velocity of the millet, the millet will be lifted and thrown out of the machine with other chaff and lighter materials. Therefore, establishing the optimum values of the independent variables (speed, beaters and millet moisture content) is crucial in order to obtain optimum machine output with good quality threshed millet. The result of this study provides standard input machine and processing variables capable of yielding the best machine output.

\section{REFERENCES}

1. A. Pradhan, S. K. Nag, S. K. Patil S. K. "Dietry management of finger millet (Eleusine coracana L., Gaerth) controls diabetes," Curr. Scie, vol. 98, no 6, 2010, pp. 281-295.

2. R. H. Myers, D. C. Montgomery, G. C. Vining, C. M. Borror, S. M. Kowalski. "Response Surface Methodology: A Retrospective and Literature Survey", J. Qual. Technol., vol. 36, 2004, pp. 53 - 77. [CrossRef]

3. P. K. Batra, R. Parsad. "Response Surface Designs”, Indian Agricultural Statistics Research Institute, Library Avenue, New Delhi, 2012, 110 012 .

4. A. M. Hossein, M. N. Abdol, H. S. Golam. "Optimization of a Cloud Point Extraction Procedure with Response Surface Methodology for the Quantification of Iron by means of Flame Atomic Absorption Spectrometry", Journal of the Serbian Chemical Society, vol. 78, no. 1, 2013, pp. 115-127. [CrossRef]
5. W. T. Chih, I.T. Lee, H. W, Chung. "Optimization of Multiple Responses Using Data Envelopment Analysis and Response Surface Methodology," Tamkang Journal of Science and Engineering, vol. 13, no. 2, 2010, pp. 197-203

6. I.M. Gana, G. Agidi, P.A. Idah, J.C. Anuonye. "Development and testing of an automated grain drinks processing machine". Journal of Food and Bioproducts Processing, Elsevier 10 4, 2017, pp. 19-31. [CrossRef]

7. A. Gbabo, I. M. Gana, S. A. Mathew. "Design, Fabrication and Testing of Millet Thresher". Net Journal of Agricultural Science, vol. 1, no. 4, 2013, pp. 100-106.

8. O. A. Aworanti, A. O. Agarry, A. O. Ajani. "Statistical Optimization of Process Variables for Biodiesel Production from Waste Cooking Oil Using Heterogeneous Base Catalyst”. British Biotechnology Journal, vol. 3, no. 2, 2013, pp. 116-132. [CrossRef]

9. P. J. Maran, S. Manikanda. (2012). "Response Surface Modeling and Optimization of Process Parameters for Aqueous Extraction of Pigments from Pea Fruit Dye”. Pigin, vol. 95, 2012, pp. 465-472. [CrossRef]

10. Xin L., \& Saka S. (2008). "Optimization of Japanese Beech Hydrolysis Treated with Batch Hot Compressed Water by Response Surface Methodology". Inter. Journal of Agricultural Biological and Engineering 1(2), 239-245.

11. K. K. Salam, A. O. Arinkoola, E. O. Oke, J. O. Adeleye. "Optimization of Operating Parameters Using Response Surface Methodology for Paraffin-Wax Deposition in Pipeline". Petroleum and Coal, vol. 56, no. 1, 2014, pp. 19-28

12. M. A. Helmy, S. I. Yousef, A. M. Badawy. "Performance evaluation of some sunflower thresher". Egyptian J Agric Res, vol. 78, no. 2, 2000, pp. 969-973.

13. K.J. Simonyan, K. C. Oni. "Performance evaluation of a motorized locust bean decorticator". J Agric Technol, vol. 9, no. 1, 2001, pp. 55-65.

14. B. Hollatz, G. R. Quick. "Combine tailings returns, part 1: the effects of combine performance and settings on tailings". In e- Proceedings of the International Conference on Crop Harvesting and Processing. Kentucky USA. ASAE Publication Number 701P1103e. St Joseph, Mich. ASAE. 2003, pp. 1-13.

\section{AUTHORS PROFILE}

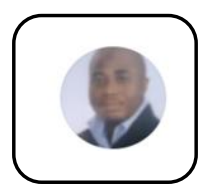

Dr. Gana, Ibrahim Mohammed, B.ENG., M.ENG. MNIAE, MNSE, R-COREN, Ph.D, a Senior Lecturer, Department of Agricultural and Bio-environmental Engineering, Federal Polytechnic Bida, Niger State, Nigeria.

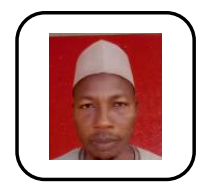

Baba Adamu Musa, B.ENG., a Lecturer I, Department of Agricultural and Bio-environmental Engineering Technology, Federal Polytechnic Nasarawa, Nasarawa State, Nigeria.

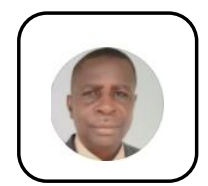

Dr. Gbabo Agidi, B.E., M.E., MNIAE, MNSE, R-COREN, Ph.D, an Associate Professor, Department of Agricultural and Bioresources Engineering, Federa University of Technology Minna, Niger State, Nigeria.

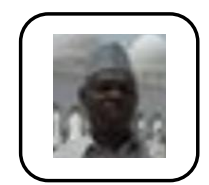

Dr. Shehu Abubakar Alhaji, H.N.D., P.G.D. M.ENG., MNIAE, MNSE, R-COREN, Ph.D, a Chief Lecturer, Department of Agricultural and Bio-environmental Engineering, Federal Polytechnic Bida, Niger State, Nigeria.

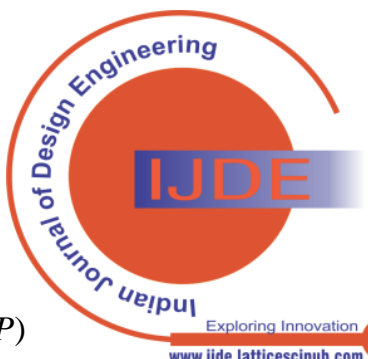

